The more satisfactory results of lithotrity at the present day, as compared with those in the early years of the operation, are no donbt mainly owing to the fact that we now employ larger evacuating catheters, which enable us to remove the broken-up fragments from the bladder much more thoroughly than was formerly the custom.

Manchester.

\section{PUSTULE SIMULATING ANTHRAX DUE TO ORGANISMS OF THE PROTEUS} GROUP.

By THOMAS ORR, M.D., B.Sc. (Pub. Health) GlasG., BACTERIOLOGIST AND ASSISTANT COUNTY MEDICAL OFFICER, WEST RIDING OF YORKSHIRE.

So much doubt exists as to the possibility of organisms of the proteus group, in the absence of other organisms, causing pathogenic lesions in man that the following case is worth recording. The case is interesting not only on account of its rarity but also because the lesion presented characteristics indistinguishable from malignant pustule, for which it was mistaken and as such treated.

A butcher, 45 years of age, first noticed a small pimple on the back of his left thumb about the middle of the metacarpal bone. This slowly increased in size but showed no signs of suppurating. There was little or no pain felt and he did not complain of feverishness or of being ill. As little discomfort was experienced, he did not seek medical advice until about a fortnight after its first appearance and until it had much increased in size. When examined by Dr. William Craik, Thurnscoe, there was found a hard raised swelling of about the size of a shilling over the area mentioned. The top of the swelling was depressed or crateriform and was dark and necrotic in appearance. At the margin of the necrotic area was distinct vesiculation and the skin around for about a quarter of an inch was dusky red with a bluish tinge. There was no evidence of pus formation. The appearances were uncommon and at once suggested malignant pustule. On the day when seen the sore was treated by injecting a solution of carbolic acid into the centre and periphery. On the next day the necrotic part had extended and the skin was inflamed to a greater extent. A crucial incision was therefore made and salicylic acid was dusted into the wound. On the following day it was thonght advisable to excise the pustule on the assumption that it was due to the anthrax bacillus. Before excision a little of the serum exuding from the previous day's incision was collected in a glass tube for bacteriological examination. Within ten days after excision a small secondary papule developed at the margin of the wound. This was incised and dusted with salicylic acid. In a few days the inflammation began to subside and the wound slowly healed.

\section{Bacteriological Examination.}

1. Serum from incised wound.-Films made from the serum and stained failed to show any organisms. A loopful spread on an agar plate gave a few white colonies which were found to be of Staphylococous albus. The presence of these organisms was probably due to contamination from the skin owing to want of aseptic precautions in collection.

2. Excised pustule. - The pustule on excision was put into sterile distilled water and next day examined. Films made from the fluid exuding from the freshly cut surface of the tissue and stained showed the presence of small bacilli with rounded ends. These were found both singly and in small groups and retained the stain by Gram's method. The surface of the tissue was seared with a hot iron and incised with a sterile knife. The fluid exuding from the cut surface was spread on nutrient agar plates. After 24 hours' incubation at $37^{\circ} \mathrm{C}$. there were found numerous small colonies of two different types. Both types of colonies occurred in about equal numbers and were found to be composed of Gram-staining bacilli to be described later. Sections of the tumour examined microscopically showed areas of necrosis surrounded by areas of leucocyte infiltration, the leucocytes being large mononuclears. In the zone between these areas of necrosis and infiltration were found many Gram-staining organisms. These were bacillary in form, irregular in size and in shape, many swollen at the ends or in the middle, and some large and spherical.
3 and 4. Speoimens from the seoondary papuie.-Two sterile cotton-wool swabs were rubbed in the centre of the secondar papule and submitted for bacteriological examination. These two specimens were taken on different days. Agar plates were smeared with the swabs, and after 24 hours' incubation they showed two kinds of colonies (A and B) similar to those isolated from specimen 2. These also were found to be composed of small Gram-staining bacilli.

Thus, from specimens 2, 3, and 4 two kinds of organisms were isolated. In their morphological and biological characters they belong to the proteus group. Both organisms were very motile and non-sporing, and retained the stain by Gram's method. Both occurred as small slender rods with rounded ends, sometimes in chains. $B$ was often arranged end to end in pairs and was slightly thicker than $A$. In old cultures both showed a variety of shapes; some of the bacilli presented irregular forms with swollen ends. On agar slopes the growths of both organisms were somewhat similar, being greyish-white and glistening or slimy, but A slightly more opaque than B. On agar plates A occurred as small greyishwhite opaque glistening colonies with a regular margin; B showed colonies each of which had an opaque greyishwhite centre and a thin transparent margin, the transparent margin being much broader than the opaque centre. A liquefied rapidly, a deep saucer-shaped hollow of liquefaction being found in the gelatine stab in 72 hours, while B liquefied much more slowly, in seven days a shallow cup of liquefaction being formed. Both pro. duced acid and gas in glucose and saccharose but not in lactose broth. A corresponds in microscopical and cultural characters with Proteus vulgaris (Hauser), while B presents characteristics similar to Proteus mirabilis (Hauser) as described by Lehmann and Neumann. It would thus appear that the sore was caused by these two organisms belonging to the proteus group, Proteus vulgaris (Hauser) and Proteus mirabilis (Hauser).

Although such infection by these organisms is unusual, it should not be unexpected when the man's version of the origin of the sore is considered. He stated that he had got in his thumb some poisonous material from bags sent out by hide and refuse dealers. These, he says, are sometimes very dirty and bad-smelling. They are used again and again without cleaning, passing from one butcher to another. In these foul-smelling bags, used for collecting fat and bones often in a putrefying condition, large numbers of organisms belonging to the proteus group are certain to be present.

Wakefieh.

\section{SUDDEN FAILURE OF RESPIRATION RESTORED BY ARTIFICIAL MEANS,}

OCCURRING DURING THE COURSE OF AN ACUTE PNEUMONIA COMPLICATED BY COMA OF URAEMIC ORIGIN,

By ROBERT KNOX, M.D. EdIN., M.R.C.S. ENG., L.R.C.P. LOND.,

MEDICAL OFFICER IN CIIARGE OF ELECTRICAL DEPARTMENT, GREAT NOR'THERN CENTRAL HOSPI'TAL, HOLLOWAY-ROAD, LONDON, N., AND

JOHN MORISON, M.B., C.M. EDIN.

THE chief points of interest in the following case are (1) the sudden failure or respiration, restored by artificial respiratory movements; and (2) the rapid progress of the fatal symptoms.

The patient was a married man aged 40 years. He gave a previous history of some bone trouble in early life which affected his left hip and knee joints and one or two ribs on the left side; probably necrosis of bone with separation and protrusion of fragments. For three days before the onset of his fatal illness he complained of headache. On the fourth day (Feb. 10th, 1909) he was seen by Dr. Morison, when he still complained of headache and sleeplessness. The temperature was $102^{\circ} \mathrm{F}$., the pulse was 100 and of moderate tension, and the tongue was furred, moist, and glutinous. There was slight cough, and the respirations were increased in frequency. Examination of the chest revealed a small area of dulness at the left base, and on auscultation there were prolonged expiration and moist crepitations over the area of 